\title{
Early predictors of phonological and morphological awareness and the link with reading: Evidence from children with different patterns of early deficit
}

\author{
ANNA J. CUNNINGHAM \\ Aston University \\ JULIA M. CARROLL \\ University of Warwick
}

Received: June 9, 2012 Accepted for publication: January 18, 2013

\section{ADDRESS FOR CORRESPONDENCE}

Anna J. Cunningham, Department of Psychology, School of Life and Health Sciences, Aston

University, Birmingham, B4 7ET, UK. E-mail: A.Cunningham@aston.ac.uk

\begin{abstract}
This study examines the contribution of early phonological processing (PP) and language skills on later phonological awareness (PA) and morphological awareness (MA), as well as the links among PA, MA, and reading. Children 4-6 years of age with poor PP at the start of school showed weaker PA and MA 3 years later (age 7-9), regardless of their language skills. PA and phonological and morphological strategies predict reading accuracy, whereas MA predicts reading comprehension. Our findings suggest that children with poor early PP are more at risk of developing deficits in MA and PA than children with poor language. They also suggest that there is a direct link between PA and reading accuracy and between MA and reading comprehension that cannot be accounted for by strategy use at the word level.
\end{abstract}

Languages of European origin are morphophonemic in structure, meaning that words are constructed via a combination of phonological and morphological rules. Accordingly, a strong association has been found between the reading and spelling of English and both phonological awareness (PA; Melby-Lervag, Lyster, \& Hulme, 2012) and morphological awareness (MA; Deacon \& Kirby, 2004). Despite the importance of these skills to literacy, relatively little is known about their antecedents in the early school years. Previous research has shown that phonological processing (PP) and language skills in early childhood are linked to the development of explicit PA and MA. However, the unique contribution of these two sets of skills to the prediction of PA and MA remains unclear. Furthermore, after these important skills have developed (typically after the first year of schooling), it is

(C) Cambridge University Press 2013. The online version of this article is published within an Open Access environment subject to the conditions of the Creative Commons Attribution-NonCommercialShareAlike licence <http://creativecommons.org/licenses/by-nc-sa/3.0/>. The written permission of Cambridge University Press must be obtained for commercial re-use. 0142-7164/13 \$15.00 
not yet known whether their influence on reading can be explained entirely by use of phonological and morphological rules to decode individual words or whether there is a broader direct effect of explicit linguistic awareness on general reading skills. The first aim of this research is to elucidate the link between early PP and language skills, and later PA and MA; the second is to investigate the concurrent links among PA, MA, phonological and morphological strategy use, and general reading skills.

\section{EARLY PREDICTORS OF PA}

PA refers to awareness of parts of speech (syllables, rhymes, and phonemes) that create meaning when combined together to make a word. It is generally accepted that implicit PA (global sensitivity to similarity between speech sounds) starts to develop before school age, whereas explicit PA (ability to consciously manipulate phonemes) develops during the early school years, stimulated by the process of learning to read (Gombert, 1992).

Given the developmental path of PA, it is not surprising that general PP skills would be a key predictor of explicit PA. PP is defined in the present paper as remembering, comparing, and learning the sound structures of words. This incorporates implicit PA (e.g., judging the similarity between words), phonological memory (e.g., repeating nonsense words), mispronunciation detection, and phonological learning (e.g., remembering nonsense names). Using structural equation modeling, Carroll, Snowling, Hulme, and Stevenson (2003) showed that implicit awareness of syllables and rhymes at the end of preschool uniquely predicted explicit PA at the beginning of school. Further, Wagner et al. (1997) report high concurrent correlations between measures of phonological memory (memory for sentences and digit span) and explicit phoneme deletion from kindergarten to fourth grade.

Other studies have suggested an additional role for broader, nonphonological language skills in the development of PA. Language is defined in the current paper as semantic and syntactic processing, including vocabulary, sentence comprehension, and correct use of morphology in context. Walley (1993) suggested that early vocabulary development led to gains in PA via a process of "lexical restructuring." The theory is that children begin by representing words as wholes and subsequently develop a representation of the sounds within words. As their vocabularies grow, words must be represented in increasing detail to differentiate them from phonologically similar neighbors. For example, sleep may be represented in a crude form in the lexicon from an early age, but when the child acquires the word sleet, he/she must develop more detailed phonological representations of both words such that they are not confused. This theory is supported by research showing a unique association between early vocabulary and later PA (Wagner et al., 1997). For example, Snowling, Gallagher, and Frith (2003) showed that a language factor based on measures of expressive and receptive language at age 4 predicted a composite PA variable at age 6 in a sample including 56 children at family risk of dyslexia. Finally, Cooper, Roth, Speece and Schatschneider (2002) showed that an oral language factor (receptive and expressive semantics, syntax, and morphology) accounted for unique variance in PA (deletion and blending) from kindergarten to second grade. However, neither of the latter two studies 
controlled for baseline PA, leading to the possibility that the influence of language was mediated by early PP abilities.

\section{EARLY PREDICTORS OF MA}

MA refers to awareness of the smallest units of meaning. Morphologically complex words are spelled by combining a "base" word with an affix or inflection. For example, an inflection can be added to alter a word's grammatical status (e.g., play-ed), or an affix can be added to change a word's semantic status such as re-do (derivational change). Sometimes, the final word maintains phonological regularity (e.g., unhappy), and sometimes it does not (e.g., cooked or emotion). It has been argued that the bulk of deviations from the alphabetic principle in English reflect the principle of maintaining a consistent spelling for morphemes, hence the importance of MA to literacy (Nagy, Berninger, \& Abbott, 2006). For example, $-e d$ is spelled the same in watched, complained, and departed, despite different pronunciations of $t / d / e d$. Explicit MA (such as the ability to produce a derivational morpheme to complete a sentence) usually develops a little later than PA, around second grade, as children are exposed to more morphologically complex words in speech and writing (Anglin, 1993; Berko, 1958).

Two broadly distinct theories have been put forward by the literature with regard to the early predictors of MA. One theory is that MA arises from a broad base of oral language skills. In the case of vocabulary, the more words children know the meaning of, the more likely they are to be able to make links between words that share morphemic units and therefore become aware of morphemes (e.g., -ness in happiness and sadness). Carlisle and Nomanbhoy (1993) found that word knowledge in kindergarten predicted morphological skills in first grade. Other research shows a high concurrent correlation between vocabulary and MA (Kieffer \& Lesaux, 2012; McBride-Chang et al., 2005; Nagy et al., 2006). McBride-Chang et al. (2005) showed that there was a reciprocal relationship between vocabulary and morphology in a large group of preschool children with gains in one leading to gains in the other. However, the relationship is not absolute; words can be learned as wholes, without reference to their morphemic structure.

An alternative view of the development of MA implicates early PP. Chiat (2001) suggests that phonological skills underlie the development of syntactic and sematic aspects of language, both of which are represented in MA. She proposes a "phonological" theory of specific language impairment (in contrast to the more traditional "grammatical" theories; Van der Lely, Rosen, \& Adlard, 2004) whereby difficulties with language stem from impaired PP and the consequent disruption of the "mapping" process between speech and meaning. The mapping process involves segmentation of a stream of speech within a "scene" into meaning-relevant chunks and segmentation of the scene into speech-chunk relevant meanings. For example, learning that the speech chunk - ed is usually accompanied by a temporal change in the "scene" results in acquisition of this past-tense morpheme. Therefore, children acquire language through the ability to recognize phonological information. Research findings provide support for this view: Carlisle and Nomanbhoy (1993) found that PA in kindergarten (syllable and phoneme deletion) predicted variance in expressive MA during first grade after vocabulary had been taken into account. 
PA training has also been shown to improve morphological skills in children with speech impairment (Kirk \& Gillon, 2007) and typical kindergartners (Casalis \& Cole, 2009; Lyster, 2002).

The different views of the development of PA and MA are not necessarily mutually exclusive. Both language and PP may act as predictors; however, it is important to test them together to determine the relative importance of the alternative routes. One way to do this is to test children with dissociated skill profiles in early childhood. For example, if early PP but not language led to MA, then children with average PP would develop better levels of MA than would children with poor PP, regardless of whether they had poor or average language. This is the approach adopted in the current study.

\section{THE MEASUREMENT OF PA AND MA}

The design of the current study necessitated testing groups of children with deficits in PP and language as well as those with average levels of skill in these two areas. Therefore, it was necessary to include measures of PA and MA that would be appropriate for a wide range of skills. Dynamic testing techniques are particularly useful for testing children with difficulties because they give an indication of a child's ability to learn given increasingly explicit prompts and therefore avoid the cycle of failure experienced by many in the case of a correct/incorrect marking system (Grigorenko \& Sternberg, 1998). They also have the added psychometric advantage of producing a greater spread of scores, therefore avoiding floor and ceiling effects (Cunningham \& Carroll, 2011). Research has shown that dynamic tests of PA are stronger predictors of subsequent reading than are static tests (Bridges, Catts, \& Diane, 2011; Spector, 1992) and that dynamic tests of morphology can effectively predict literacy (Larsen \& Nippold, 2007; Wolter, Barger, Pike, Atwood, \& Martin, 2011). For the current study, a dynamic test of phoneme deletion was designed, because phoneme deletion tasks have consistently been shown both to predict subsequent reading in young children better than detection or oddity tasks and to display higher reliability (Hulme et al., 2002).

With regard to MA, the two most commonly used explicit measures are production (e.g., "Help. Father tells me that I am a good helper") and decomposition tasks (e.g., "Driver. Children are too young to drive"; Berko, 1958; Carlisle, 2000; Carlisle \& Nomanbhoy, 1993; Deacon \& Kirby, 2004; Kieffer \& Lesaux, 2012). In both cases, children must produce an explicit response that requires conscious awareness of the target morpheme. Both tasks have also been shown to predict reading and to have high reliability (Apel \& Lawrence, 2011). On the basis of this, a dynamic measure of morpheme production was designed for use in the present study.

\section{THE LINKS AMONG PA, MA, AND READING}

The link between PA and reading is well established. A large body of research shows that the ability to segment and blend phonological units by referral to grapheme-phoneme correspondences (the alphabetic principle) leads to, and is aided by, the ability to read and spell words (e.g., Melby-Lervag et al., 2012). By 
comparison, the link between MA and word reading is relatively underresearched. Morphological knowledge may contribute to word reading accuracy in at least two ways; first, by reducing the number of "units" that need to be processed (e.g., the -ful in forgetful can be read as one morpheme or three phonemes), and second, by leading to correct pronunciation of words that deviate from the alphabetic principle in order to conserve the spelling of morphemes (e.g., emotion is read as emo-shun, not emot-ion). Many studies have shown that MA contributes variance to word reading above and beyond PA (Berninger, Abbott, Nagy, \& Carlisle, 2010; Nagy et al., 2006; Wolter, Wood, \& D'Zatko, 2009). In addition, a recent meta-analysis showed that training in morphology led to improved literacy skills, particularly for less able readers (Bowers, Kirby, \& Deacon, 2010). However, some studies have shown an effect of MA on nonword reading but not on real-word reading (Casalis \& Louis-Alexandre, 2000; Deacon \& Kirby, 2004; Mahony, Singson, \& Mann, 2000), or no effect at all (Nagy, Berninger, Abbott, Vaughan, \& Vermeulen, 2003), so the relationship remains unclear.

Research on reading comprehension has yielded more consistent results. An awareness of morphemes helps children to understand the meaning of morphologically complex words (e.g., that happiness is a state of being happy), such that comprehension of sentences containing such words is improved (Carlisle, 2000). MA also makes an additional contribution by helping children to understand the syntactic structure of sentences (e.g., that "Mike played in the park" is referring to an event in the past, with the action being "to play"). Several studies have shown that MA contributes to reading comprehension beyond vocabulary (Deacon \& Kirby, 2004; Nagy et al., 2003). PA generally does not predict reading comprehension once word reading has been controlled (Muter, Hulme, Snowling, $\&$ Stevenson, 2004).

\section{THE RELATIONSHIPS AMONG PA, MA, AND PHONOLOGICAL AND MORPHOLOGICAL STRATEGY USE}

Although children may be aware of phonemes and morphemes within words, this does not necessarily mean that they use this information to help them to read and spell. For example, a child may be able to segment the nonword guf into its composite phonemes $(g-u-f)$ when presented with the word orally, but he may not apply this ability when presented with the word in print (thus leading to the wrong pronunciation, e.g., gaf). Similarly, a child may know of the morpheme dis and be able to identify it in speech, but he/she may still decode the nonword dishope as dish-ope. It may be that PA and MA implicate general reading only to the extent that phonological and morphological strategies are used at the word level.

In order to investigate this hypothesis, it was necessary to devise measures of strategy use. Nonwords were used in order to separate the influence of wholeword orthographic knowledge from that of PA or MA (e.g., thankful can be read if recognized as a whole, whereas to read trangful would require segmentation into trang and ful, and therefore call upon MA). One difficulty is that phonologically regular words such as trangful can also be read on the basis of phonological rules (the alphabetic principle) and therefore may not be tapping MA. This hypothesis is supported by the results of Nagy et al. (2006), who tested a large group of 
fourth- to ninth-graders on five different measures of their ability to decode morphologically complex words. They found that a nonword reading measure (phonological decoding) predicted all five measures of morphological decoding over and above MA, implying that children were using phonological strategies to help decode morphemes. Nunes, Bryant, and Olsson (2003) addressed this issue by devising separate tests to tap use of phonological and morphological strategies to read and spell words. One set of words required the child to identify a morpheme in order to obtain the correct pronunciation (e.g., the un in universe and unhappy is pronounced differently because uni and un are different morphemes), whereas the other set of words required the child to have knowledge of a phonological rule (e.g., the split vowel-e digraph as in hope). The authors found that training in MA improved use of morphological strategies for spelling and performance on a standardized reading test.

The current study uses similar measures in order to investigate whether the link among MA, PA, and word reading/reading comprehension can be explained by the use of morphological and phonological strategies for nonword reading/spelling. We anticipate that phonological and morphological strategies for nonword reading will predict word reading accuracy, whereas PA and MA will make no unique contribution. Finally, we expect both morphological strategy use and MA to uniquely predict reading comprehension.

\section{THE CURRENT STUDY}

This research follows up with children initially recruited for a previous study comparing children at risk of reading difficulty with no-risk controls (Carroll \& Myers, 2010). As such, it presented an ideal sample to access children with early PP and language deficits. In order to contrast the roles played by these correlated skills, four subgroups were selected based on measures of language and PP taken from the whole sample at Time 1 (kindergarten or first grade). Two composite variables were created based on four measures of PP (implicit PA, mispronunciation detection, phonological memory, and learning), and three measures of language (expressive vocabulary, sentence comprehension, and word structure). One group showed both low PP and low language (double deficit), a second showed low PP and average language (single PP deficit), a third showed low language and average PP (single language deficit), and a fourth group were average on both sets of measures (no deficit). These groups were tested again 3 years later (third to fourth grade) on dynamic tests of MA and PA, phonological and morphological strategy use for reading and spelling, text reading accuracy, and comprehension. Three main questions were addressed. Mean comparisons between groups and regressions were used to address the first question and regressions were used to address the second and third questions.

1. What is the predictive effect of early PP and language skills on later PA, MA, and morphological and phonological strategy use for reading and spelling?

2. Are PA and MA linked to phonological and morphological strategy use for literacy? 
3. Is there a direct link among PA, MA, and reading accuracy and comprehension that cannot be explained by use of phonological or morphological strategies at the word level?

\section{METHOD}

\section{Participants}

Four subgroups were identified from 198 children initially tested during kindergarten or first grade (UK Reception or Year 1) when they were 4-6 years old (mean $=5$ years, 6 months $[5 ; 6]$, range $=4 ; 5-7 ; 5)$. Eighty-two children were at risk of reading difficulties because they had a first-degree relative with dyslexia $(n=46)$ or involvement in speech and language therapy $(n=36)$, and 116 children had no known risk factors. On the basis of the Time 1 scores for PP (composite of four measures) and language (composite of three measures), 27 children were identified as having a double deficit (low PP and low language), 17 a single PP deficit (low PP and average language), 23 a single language deficit (average PP and low language), and 131 no deficit (average PP and average language). The 7 children who scored poorest for language (standard score $<60$ ) were not tested at Time 2 because it was felt that they were too severely impaired to understand the instructions for the dynamic tasks. This left 20 children in the double deficit group and 191 children across all four subgroups. Because average scores for PP and language were higher in the no deficit group compared to the single deficit groups (e.g., 105.8 for language in the no deficit group vs. 98.0 for language in the single PP deficit group), a matched no deficit group of 24 children with scores for PP and language similar to the single deficit groups was selected.

Of the 191 children, 164 (85\% of the original sample) were retested 3 years later during third or fourth grade (UK year 3 or 4) at age 7-9 years (mean = $8 ; 6$, range $=7 ; 2-10 ; 3$ ). Nineteen children had moved school. Of these, 10 were unlocatable, 7 had emigrated, 1 had been taken into care, and 1 moved out of the area. A further 4 children were at a school that declined to participate, 2 parents did not return the consent form and could not be contacted, and 1 parent and 1 child refused consent. Comparison between the 164 recaptured and the 27 lost children revealed no significant difference in their Time 1 PP scores, $t(189)=$ $0.04, p=.97$; however, language scores were poorer in the lost children, $t(187)=$ $-2.55, p<.05$. This is likely because parents of children with poor language were less likely to fill in and return the parental consent form.

The final sample tested at Time 2 included 18 double deficit, 15 single PP deficit, 17 single language deficit, and 114 no deficit children ( 24 of whom were in the matched no deficit group). See Table 1 for mean scores in each subgroup. Due to time constraints, only the matched no deficit group were tested on the dynamic tasks. All 114 no deficit children were tested on the strategy-use and reading tasks. This resulted in a final sample of 74 children for the dynamic tasks. All children spoke English at home as their main language. The majority of children were attending one of 8 schools $(n=121)$, and the remaining 43 were distributed over a further 32 schools in the Midlands area of the United Kingdom. Schools represented a wide range of socioeconomic circumstances (Byrne, 1993). 
Table 1. Means and standard deviations for the subgroups

\begin{tabular}{|c|c|c|c|c|c|}
\hline \multirow[b]{3}{*}{ Subgroup } & \multirow[b]{3}{*}{ Max. } & \multicolumn{2}{|c|}{ Low PP } & \multicolumn{2}{|c|}{ Average PP } \\
\hline & & $\begin{array}{l}\text { Double Deficit, } \\
\text { Low Language } \\
\quad(N=18)\end{array}$ & $\begin{array}{l}\text { Single Deficit, } \\
\text { Average Lang. } \\
\quad(N=15)\end{array}$ & $\begin{array}{l}\text { Single Deficit, } \\
\text { Low Lang. } \\
(N=17)\end{array}$ & $\begin{array}{l}\text { No Deficit, } \\
\text { Average Lang } \\
\quad(N=24)\end{array}$ \\
\hline & & $M(S D)$ & $M(S D)$ & $M(S D)$ & $M(S D)$ \\
\hline \multicolumn{6}{|l|}{ Variable at Time 1} \\
\hline Age (months) & - & $66.8(10.0)$ & $67.7(7.2)$ & $65.4(6.5)$ & $66.9(7.5)$ \\
\hline Phonological processing ${ }^{a}$ & - & $79.7(6.9)$ & $83.1(5.6)$ & $95.6(5.0)$ & $97.2(6.4)$ \\
\hline Language $^{a}$ & - & $77.7(5.8)$ & $98.0(7.9)$ & $80.8(6.4)$ & $98.6(6.7)$ \\
\hline \multicolumn{6}{|l|}{ Variable at Time 2} \\
\hline Age (months) & - & $102.3(10.5)$ & $105.3(7.9)$ & $102.2(9.4)$ & $103.9(8.7)$ \\
\hline Dynamic phoneme & 104 & $67.8(21.0)$ & $62.7(21.2)$ & $75.1(20.5)$ & $76.0(15.5)$ \\
\hline Phonological reading & 11 & $5.1(2.1)$ & $5.5(2.5)$ & $6.5(2.5)$ & $6.4(2.9)$ \\
\hline Phonological spelling & 13 & $6.0(3.2)$ & $6.3(3.7)$ & $8.2(2.4)$ & $8.0(3.4)$ \\
\hline Dynamic morpheme & 84 & $67.9(6.8)$ & $70.3(4.6)$ & $70.5(7.6)$ & $72.9(5.1)$ \\
\hline Morphological reading & 11 & $2.4(2.0)$ & $2.8(2.2)$ & $2.9(2.1)$ & $3.4(2.6)$ \\
\hline Morphological spelling & 26 & $11.3(4.9)$ & $11.4(5.0)$ & $13.2(5.4)$ & $13.8(5.1)$ \\
\hline Reading accuracy $^{b}$ & - & $42.7(7.9)$ & $44.9(8.4)$ & $47.8(6.2)$ & $49.0(9.2)$ \\
\hline Reading comprehension ${ }^{b}$ & - & $48.5(5.5)$ & $52.7(8.2)$ & $52.5(7.7)$ & $51.5(8.5)$ \\
\hline
\end{tabular}

Note: All other scores are raw if not standard or Rasch based. Reading accuracy and reading comprehension are the York

Assessment of Reading for Comprehension. PP, phonological processing.

${ }^{a}$ Standard score (original no-risk group $M=100, S D=15$ ).

${ }^{b}$ Rasch-based ability score. 


\section{Calculation of subgroups}

The "core language score" from the Clinical Evaluations of Language Fundamentals (Wiig, Secord, \& Semel, 2006) was used as a measure of language. The score represented a composite of three measures: expressive vocabulary (naming pictures), sentence structure (a sentence comprehension task where children had to point to a picture that depicted a sentence), and word structure (an expressive morphological task where children had to correctly inflect a given word, e.g., Here is one girl. There are two girls). Correlations between the three measures were high $(r=.49-.56)$. Because the standard scores varied by age in our sample, core language scores were residualized for age (age was entered into a regression predicting core language and the standard residual scores saved), then standardized against the original no-risk group $(n=116)$ such that this group had a mean score of 100 and a standard deviation of 15. A low language score was designated as approximately $1 S D$ below the control group mean (standard score $\leq 86.5$ ). Fifty children fulfilled this criterion. ${ }^{1}$ This is larger than the standard $16 \%$ of the sample because of the high numbers of high-risk children included in the sample.

A composite score was calculated based on four PP measures taken at Time 1: initial phoneme matching (matching words beginning with the same sound), nonword repetition (repeating nonwords), mispronunciation detection (saying whether a word was pronounced correctly or not), and nonword learning (learning phonologically similar names of animals). Correlations between measures were medium $(r=.36-.47)$. Raw scores for each test were residualized for age then standardized against the original no-risk group such that this group had a mean score of 100 and a standard deviation of 15 . A "factor" score was calculated by taking the mean standard score for the four tests. A low PP score was designated as approximately $1 S D$ below the control group mean (standard score $=89.61$; see Note 1 ). Fortythree children fulfilled this criterion. Further details of the Time 1 measures used are contained in Carroll and Myers (2010).

\section{Time 2 testing procedure}

Children were tested in their homes $(n=35)$, at the university $(n=3)$, or in a quiet corner of their school $(n=126)$. Testing was split into two sessions of approximately $30 \mathrm{~min}$. Dynamic tasks were administered in a third session lasting around $40 \mathrm{~min}$. Nonword decoding, nonword spelling, and reading comprehension were administered either by the first author or by one of two trained research assistants. The first author administered all dynamic tasks.

\section{Materials}

Dynamic phoneme deletion. This task was designed based on the dynamic phoneme segmentation task presented in Cunningham and Carroll (2011). Children were asked to delete a phoneme from 13 nonwords ranging in length from two to seven phonemes and involving a mix of initial, final, or medial phoneme deletion. Nonwords were chosen to minimize dependence on orthographic 
information (Castles, Holmes, Neath, \& Kinoshita, 2003). Six phonemes were deleted from consonant clusters (e.g., "l" from "flirmab"), and seven consonants were deleted from before or after vowels (e.g., " $t$ " from "dreet"; see Appendix A). Children were given up to nine increasingly explicit prompts (negatively coded) to help them arrive at the correct answer (e.g., "What's the first sound in 'flirmab' to 'put $f$ and irmab' together to make ..."). The question was repeated after each prompt. Sample-specific reliability was high (Cronbach $\alpha=0.87$ ).

Dynamic morpheme production. This task was designed based on the Wug test devised by Berko (1958). Children were asked to complete 14 sentences by adding an inflection or affix to a nonword. Eight items required the addition of an inflection (e.g., "This man knows how to zib. He is zibbing."), whereas six items required a derivational change through the addition of an affix (e.g., "This dog has quocks on him. He is a quocky dog.") Children were given up to 6 increasingly explicit prompts (negatively coded) using a real-word example to help them achieve the correct response (e.g., "This dog has spots on him. He is a spotty dog."). The question was repeated after each prompt. All words were phonologically transparent (the pronunciation of the base remained unchanged in the derived form), and each item was accompanied by two pictures, one to go with the nonword and one to go with the real word prompt (see Appendix A). Sample-specific reliability was medium-high (Cronbach $\alpha=0.76$ ).

Phonological and morphological strategy use for reading. This test was based on the pseudoword reading task presented in Nunes et al. (2003). Children were asked to read aloud a list of 16 morphologically complex nonwords (10 included a derivational morpheme, 4 an inflection, and 2 were compound words) and 4 simple nonwords. Ten items were from the Nunes test, and 10 were new items (see Appendix A). The phonological score was based on the number of phonologically appropriate responses for the 4 simple words: bish, mive, amphal, and lave, and the 7 morphologically complex words where either the morphemic or the phonemic pronunciation was considered phonologically appropriate: unishaped (uni-shaped or un-i-shaped), cophant (cop-hant or cofant), lishing, kished, healthive, unimpute, and unirritate. The morphological score was based on the total number of responses sensitive to the morphological status of the item, where that affected pronunciation (adherence to phonological rules only would result in a different pronunciation): the $i v$ of healthive (health-iv not health-ive), dancive, amazive; the $h$ of mishope (mis-hope not mish-ope), mishammer, hophouse, and anthive; the uni of unishaped, unimatch, unisided; and the ive of anthive. Sample-specific reliabilities were medium-high (Cronbach $\alpha$ phonological reading $=0.77$, morphological reading $=0.71)$.

Phonological and morphological strategy use for spelling. This test was based on the pseudoword spelling test presented in Nunes et al. (2003). Children were presented with 13 sentences containing a nonword stem and a missing derived or inflected form of this stem. The experimenter read the complete sentence up to two times, and the child filled in the missing word accordingly (e.g., "We usually deave in the morning, but yesterday we deaved in the afternoon."). For the 
morphological score, up to 2 points were available for each word (1 point for preservation of the stem and 1 for correct spelling of the morpheme). For the phonological score, any phonologically plausible spelling was awarded 1 point. Spellings were regarded as "phonologically plausible" if each phoneme was spelled in that way at least once in the Medical Research Council psycholinguistic database (Wilson, 1988). For example, for the word deaved, the spelling deaved would gain 2 morphological points for representing both the stem and the affix correctly. The spelling deavd would gain only 1 morphological point, for representing the stem correctly. Both would gain a phonological point for being phonologically plausible. Five sentences were taken from Nunes original test, and 8 new sentences were added. Seven target nonwords contained one or two derivational morphemes, and 6 contained an inflection. Sample-specific reliabilities were mediumhigh (Cronbach $\alpha$ phonological spelling $=0.79$, morphological spelling $=$ $0.82)$.

The York Assessment of Reading for Comprehension. For this assessment (Snowling et al., 2009), children were asked to read two passages of text. Passages of an appropriate level were selected based on the child's grade level. At the end of each passage, eight comprehension questions were asked. The number of reading errors (1 per mispronounced, substituted, or omitted word) and the number of correct answers on the comprehension questions were recorded, providing scores for reading accuracy and reading comprehension. In each case, raw scores were converted to Rasch-based ability scores and then averaged across the two passages to obtain a final score. Published reliabilities range from 0.75 to 0.94 for reading accuracy and 0.71 to 0.84 for reading comprehension, depending on the passages given.

\section{RESULTS}

All variables apart from dynamic morpheme showed approximately normal distributions; therefore, raw scores were used. Square root transformation of the negatively skewed dynamic morpheme variable led to a distribution that conformed to normality; therefore, transformed scores were used. Skew and kurtosis values were $<1$ for all variables, indicating appropriateness for parametric tests (Osborne, 2002). All variables conformed to the assumptions of regression (independent errors, no multicollinearity, normally distributed errors, homoscedasity, and linearity).

\section{The effect of early $P P$ and language deficits on later $P A, M A$, and phonological/ morphological strategy use for reading and spelling}

Subgroup analyses. Table 1 shows means and standard deviations for the subgroups. Two-way ANOVAs were conducted with the PP group and the language group as orthogonal factors, and age at Time 2 as a covariate. Children from the matched control group were used, such that there were 33 children with low PP and 41 with average PP, then 35 with low language and 39 with average language. In the case of PA, the mean level was higher in the double deficit compared to the 
single PP deficit group. This is most likely because a large number of the double deficit group were receiving additional support in or outside school that included phonic work.

On the dynamic PA task, children with low PP at Time 1 had significantly poorer PA at Time $2, F(1,69)=4.7, p<.05, \eta^{2}=0.06$, regardless of language group, $F(1,69)=0.24, p=.62, \eta^{2}<0.01$. There was no significant interaction between the PP group and the language group, $F(1,69)=0.17, p=$ $.68, \eta^{2}<.01$, indicating that children in the double deficit groups displayed the level of performance that would be expected given their difficulties in each area.

For the dynamic morpheme task, children with poor PP at Time 1 had significantly poorer MA at Time $2, F(1,69)=4.60, p=.04, \eta^{2}=0.06$. Again, language group was not significant, $F(1,69)=2.14, p=.15, \eta^{2}=0.03$, and there was no significant interaction, $F(1,69)<0.01, p=.96, \eta^{2}<0.01$.

For phonological reading, the effect of PP group was near significant, $F(1,69)=$ $3.5, p=.06, \eta^{2}=0.05$, whereas the effect of language group was not, $F(1,69)=$ $0.03, p=.86, \eta^{2}<0.01$. There was no significant interaction, $F(1,69)=0.24$, $p=.63, \eta^{2}<0.01$. For phonological spelling, the effect of PP group was significant, $F(1,69)=6.6, p<.05, \eta^{2}=0.09$, whereas language group was not, $F(1$, $69)<.01, p=.95, \eta^{2}<0.01$. Again, there was no significant interaction, $F(1$, 69) $=0.14, p=.71, \eta^{2}<0.01$.

For morphological reading, the effect of neither PP group, $F(1,69)=0.95, p=$ $.33, \eta^{2}=0.01$, nor language group, $F(1,69)=0.44, p=.51, \eta^{2}<0.01$, was significant. There was no significant interaction, $F(1,69)=0.03, p=.87$, $\eta^{2}<0.01$. Finally, for morphological spelling, PP group had a near-significant effect, $F(1,69)=3.7, p=.06, \eta^{2}=0.05$, whereas language group was nonsignificant, $\left.F(1,69)<0.01, p=.98, \eta^{2}<0.01\right)$. Again, there was no significant interaction, $F(1,69)=0.09, p=.76, \eta^{2}<0.01$.

Regression analyses. Table 2 shows correlations between measures. In order to utilize the extra information provided by continuous data for PP and language, regressions were performed across the whole sample predicting Time 2 PA, MA, nonword reading, and spelling strategies, from PP and language at Time 1. Due to the relatively large age range represented, age at Time 2 was partialed out. In order to maximize sample size, data from all 164 children was used for the nonword measures. Table 3 shows the results of the six simultaneous regressions. PP significantly predicted PA, MA, and phonological and morphological strategy use for nonword reading and spelling. Language made an additional contribution to MA only.

\section{The relationships among PA and MA and strategy use for reading/spelling}

Table 4 shows the results of four simultaneous regressions predicting nonword reading and spelling strategy use from dynamic PA and MA. PA predicted all four nonword measures, but MA made no significant additional contribution. 
Table 2. Correlations between measures at Time 1 and Time 2

\begin{tabular}{|c|c|c|c|c|c|c|c|c|c|c|c|}
\hline Variable & 1 & 2 & 3 & 4 & 5 & 6 & 7 & 8 & 9 & 10 & 11 \\
\hline \multicolumn{12}{|l|}{ Time 1} \\
\hline 1. Phonological processing & - & $.60 * *$ & $.40^{* *}$ & $.52 * *$ & $.56 * *$ & $.34 * *$ & $.35^{* *}$ & $.49 * *$ & $.52 * *$ & $.44 * *$ & .04 \\
\hline 2. Language & & - & .03 & $.33 * *$ & $.37 * *$ & $.41 * *$ & $.31 * *$ & $.39 * *$ & $.42 * *$ & $.54 * *$ & .06 \\
\hline \multicolumn{12}{|l|}{ Time 2} \\
\hline 3. Dynamic phoneme & & & - & $.64 * *$ & $.68 * *$ & $.42 * *$ & $.33^{* *}$ & $.50 * *$ & $.59 * *$ & .15 & -.16 \\
\hline 4. Phonological reading & & & & - & $.77 * *$ & $.40^{* *}$ & $.55^{* *}$ & $.70^{* *}$ & $.75^{* *}$ & $.41 * *$ & $.20 *$ \\
\hline 5. Phonological spelling & & & & & - & $.44^{* *}$ & $.49^{* *}$ & $.83 * *$ & $.76^{* *}$ & $.42 * *$ & $.20^{*}$ \\
\hline 6. Dynamic morpheme & & & & & & - & .10 & $.34 * *$ & $.38 * *$ & $.30 * *$ & .06 \\
\hline 7. Morphological reading & & & & & & & - & $.54 * *$ & $.59 * *$ & $.33 * *$ & $.21 * *$ \\
\hline 8. Morphological spelling & & & & & & & & - & $.77 * *$ & $.48 * *$ & $.27 * *$ \\
\hline 9. Reading accuracy & & & & & & & & & - & $.53 * *$ & $.26 * *$ \\
\hline 10. Reading comprehension & & & & & & & & & & - & $.30 * *$ \\
\hline 11. Age & & & & & & & & & & & - \\
\hline
\end{tabular}

Note: Correlations are bivariate (Pearson $r$ ). Dynamic phoneme and dynamic morpheme, $n=74$. All other measures, $n=164$.

$* p<.05$ (two tailed). ${ }^{* *} p<.01$. 
Table 3. Regressions predicting phonological and morphological measures at Time 2 from phonological processing and language at Time 1

\begin{tabular}{|c|c|c|c|c|c|c|c|c|}
\hline \multirow[b]{3}{*}{ Variable at Time 1} & \multicolumn{8}{|c|}{ Dependent Variable at Time 2} \\
\hline & \multicolumn{4}{|c|}{ Dynamic Phoneme } & \multicolumn{4}{|c|}{ Dynamic Morpheme } \\
\hline & $B$ & $S E B$ & $\beta$ & $R^{2}$ & $B$ & $S E B$ & $\beta$ & $R^{2}$ \\
\hline Age (Time 2) & -0.34 & 0.24 & -0.15 & $.19^{*}$ & $<0.01$ & 0.01 & 0.03 & $.22 * *$ \\
\hline $\begin{array}{r}\text { Phonological } \\
\text { processing }\end{array}$ & 0.87 & 0.23 & $0.42 * *$ & & 0.02 & 0.01 & $0.25 *$ & \\
\hline Language & -0.12 & 0.19 & -0.07 & & 0.03 & 0.01 & $0.34 * *$ & \\
\hline & \multicolumn{4}{|c|}{ Phonological Reading } & \multicolumn{4}{|c|}{ Morphological Reading } \\
\hline Age (Time 2) & 0.05 & 0.02 & $0.18 * *$ & $.29 * *$ & 0.05 & 0.02 & $0.19 *$ & $.17 * *$ \\
\hline $\begin{array}{l}\text { Phonological } \\
\text { processing }\end{array}$ & 0.12 & 0.02 & $0.49 * *$ & & 0.05 & 0.02 & $0.24 * *$ & \\
\hline Language & $<0.01$ & 0.02 & 0.02 & & 0.02 & 0.01 & 0.15 & \\
\hline & \multicolumn{4}{|c|}{ Phonological Spelling } & \multicolumn{4}{|c|}{ Morphological Spelling } \\
\hline Age (Time 2) & 0.06 & 0.02 & $0.17 *$ & $.32 * *$ & 0.14 & 0.04 & $0.24 * *$ & $.30 * *$ \\
\hline $\begin{array}{r}\text { Phonological } \\
\text { processing }\end{array}$ & 0.15 & 0.02 & $0.51 * *$ & & 0.19 & 0.04 & $0.39 * *$ & \\
\hline Language & 0.01 & 0.02 & 0.05 & & 0.05 & 0.03 & 0.14 & \\
\hline
\end{tabular}

Note: Dynamic phoneme and dynamic morpheme, $n=74$. Nonword reading and spelling measures, $n=164$.

$* p<.05 . * * p<.01$.

\section{Predicting reading accuracy and comprehension}

Concurrent relationships across the sample were examined using regressions predicting Time 2 reading accuracy and comprehension from Time 2 PA, MA, and phonological and morphological reading. Because our interest was in the possible mediating role of strategy use for reading, the spelling measures were not entered. Table 4 shows the results of two simultaneous regressions with age at Time 2 partialed out. Dynamic PA, phonological reading, and morphological reading were unique predictors of reading accuracy, whereas MA was the only unique predictor of reading comprehension.

\section{DISCUSSION}

The first focus of this study was to contrast the contribution of early PP and language skills on later PA, MA, and strategy use at the word level. A combination of subgroup and regression analyses were used to show which groups were most at risk of developing difficulties, as well as to reveal broader predictive trends. The 
Cunningham \& Carroll: Early predictors of PA and MA

Table 4. Regressions predicting strategy use for nonword reading/spelling and reading accuracy and comprehension

Dependent Variable at Time 2

\begin{tabular}{|c|c|c|c|c|c|c|c|c|}
\hline \multirow[b]{2}{*}{ Variable at Time 2} & \multicolumn{4}{|c|}{ Phonological Reading } & \multicolumn{4}{|c|}{ Morphological Reading } \\
\hline & $B$ & $S E B$ & $\beta$ & $R^{2}$ & $B$ & SE B & $\beta$ & $R^{2}$ \\
\hline Age & 0.05 & 0.03 & 0.16 & $.45 * *$ & 0.05 & 0.03 & 0.18 & $.14 *$ \\
\hline Dynamic phoneme & 0.08 & 0.01 & $0.61 * *$ & & 0.04 & 0.01 & $0.39 * *$ & \\
\hline \multirow[t]{2}{*}{ Dynamic morpheme } & 0.41 & 0.28 & 0.14 & & -0.19 & 0.31 & -0.08 & \\
\hline & \multicolumn{4}{|c|}{ Phonological Spelling } & \multicolumn{4}{|c|}{ Morphological Spelling } \\
\hline Age & 0.06 & 0.03 & $0.17 *$ & $.52 * *$ & 0.18 & 0.06 & $0.31 * *$ & $.35^{* *}$ \\
\hline Dynamic phoneme & 0.11 & 0.02 & $0.64 * *$ & & 0.13 & 0.03 & $0.52 * *$ & \\
\hline \multirow[t]{2}{*}{ Dynamic morpheme } & 0.58 & 0.33 & 0.16 & & 0.33 & 0.60 & 0.06 & \\
\hline & \multicolumn{4}{|c|}{ Reading Accuracy } & \multicolumn{4}{|c|}{ Reading Comprehension } \\
\hline Age & 0.03 & 0.08 & 0.03 & $.56 * *$ & 0.14 & 0.10 & 0.17 & $.15^{*}$ \\
\hline Dynamic phoneme & 0.11 & 0.05 & $0.26^{*}$ & & -0.01 & 0.06 & -0.03 & \\
\hline Phonological reading & 1.02 & 0.38 & $0.33 * *$ & & 0.21 & 0.48 & 0.07 & \\
\hline Dynamic morpheme & 0.99 & 0.84 & 0.11 & & 2.19 & 1.07 & $0.26^{*}$ & \\
\hline Morphological reading & 1.00 & 0.35 & $0.27 * *$ & & 0.40 & 0.44 & 0.12 & \\
\hline
\end{tabular}

Note: All measures, $n=74$. Reading accuracy and reading comprehension is the York Assessment of Reading for Comprehension.

$* p<.05 . * * p<.01$.

second focus was to elucidate the links among PA, MA, strategy use, and general reading skills. A series of regressions were performed to show which skills were most predictive of reading accuracy and comprehension; Figure 1 summarizes the significant effects found.

\section{The effect of early PP and language skills on later PA, MA, and strategy use}

The results clearly showed that the two groups of children with poor PP were consistently at risk for difficulties in both phonological and morphological areas. The effect applied to "pure" measures of PA and MA as well as the ability to apply this awareness to the reading and spelling of nonwords (with the exception of morphological reading). Although PP did not quite reach significance for phonological reading and morphological spelling, the trend for children with average PP to do better than their low PP peers was clear.

The subgroup analyses were supported by the results of the regressions, which revealed that PP at Time 1 predicted PA, MA, and all four measures of strategy use. These findings suggest that children with poor language but good phonology at the start of school have relatively good outcomes. Theoretically, the importance 
Time 1

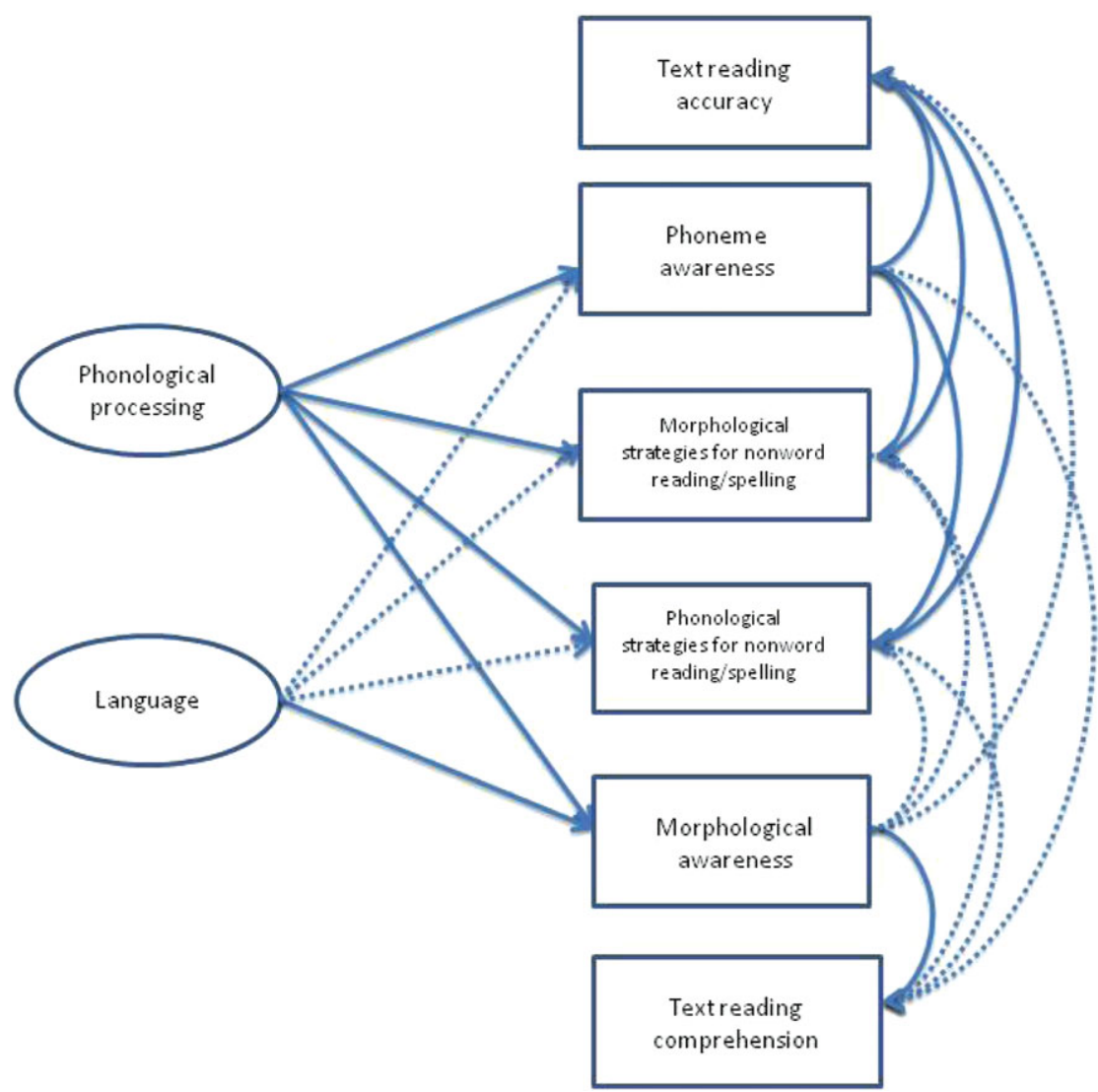

Figure 1. (Color online) The relationships between variables. The results are based on regression analyses reported in Tables 3 and 4. Significant effects are indicated by solid lines/curves, and nonsignificant effects are indicated by dashed lines/curves.

of early PP skill to later morphological knowledge supports Chiat's (2001) phonological mapping theory. As children learn a wider variety of complex words, good PP skill may allow them to detect and process morphological regularities and affixes.

Regression analyses showed that language made a unique contribution to explicit MA. Theoretically, it makes sense that language should predict MA because vocabulary and syntax are strongly related to the construction and understanding of morphologically complex words (McBride-Chang et al., 2005). It is therefore surprising that language group did not reach significance in the subgroup analyses. A possible explanation may be that the difference in language scores between the 
low and the average language groups ( $~ 18$ points $)$ may not have been large enough to result in significant group differences for language.

More interesting is the finding that language did not contribute any unique variance to the prediction of explicit PA. This is contrary to the findings of Copper et al. (2002) and Snowling et al. (2003). One explanation is that the influence of language on PA in the latter studies was mediated by early PP skills; therefore, when PP was controlled for in the current study, the effect of language disappeared. However, this does not explain the unique contribution found by Wagner et al. (1997) and Carroll et al. (2003), while controlling for an earlier measure of PA. However, in each case only one "construct" within PP was partialed out; syllable/rime awareness in Carroll et al. (2003) and PA in Wagner et al. (1997). It may be that broader PP skills, including phonological memory, mediate the link between language and PP. Finally, this finding does not support Walley's (1993) lexical restructuring hypothesis. One may argue that this hypothesis would not predict a unique contribution from language, because vocabulary and early PA (as represented by PP in the current study) are intimately linked and one may lead to the other. However, the very low correlation between language and dynamic PA $(r=.03)$ would argue against this. It may be that language is implicated in the development of general PA but is not so important to explicit phoneme deletion.

With regard to the effect of PP, but not language on use of phonological and morphological strategies for reading and spelling, this underlines the importance of early phonological skills in later morphological knowledge. However, the effects were probably exacerbated by the use of nonwords in the tests. Decoding of nonwords is almost totally reliant on phonological skills. Use of real words may have revealed more reliance on general language because lexical-semantic routes may have been accessed to lead to the correct response (Coltheart, Rastle, Perry, Langdon, \& Ziegler, 2001).

\section{The links among PA, MA, and phonological and morphological strategy use for literacy}

Regressions showed that both phonological and morphological strategy use for nonword reading and spelling were predicted by PA and not MA. This is a surprising result, given that the purpose of the morphological reading/spelling measures was to tap the application of MA to literacy. One explanation is that the children in our sample were using phonological knowledge to decode morphologically complex words, for example, reading mis as three phonemes rather than one morpheme. In addition, as explained earlier, use of PA to help decode and spell at the word level would have been enhanced by the use of nonwords. The results are in line with the findings of Nagy et al. (2006), who found that on a measure of decoding morphologically complex words that were phonologically transparent, MA did not predict unique variance over and above a phonological decoding task, suggesting that children were using phonological strategies to decode complex words. On the basis of these results, it may be suggested that children in third and fourth grades use their knowledge of phonology more so than morphology to help them read and spell. This fits in with the way in which reading is taught in the 
United Kingdom; children are explicitly taught how to use phonological strategies (e.g., segmentation into phonemes) to decode and spell words (Rose, 2006), but tuition in morphological strategies is much less common (Nunes \& Bryant, 2006).

\section{The influence of PA, MA, and phonological and morphological strategy use on reading accuracy and comprehension}

PA and phonological and morphological reading made a unique contribution to the prediction of reading accuracy. The effect of PA on reading accuracy is in line with a large body of research in this area and reflects how an awareness of speech sounds is important for word reading (Melby-Levarg et al., 2012). The interesting finding is that this effect remained after phonological strategy use had been partialed out. Because the relationships tested were concurrent, it was not possible to show mediation; a three time point longitudinal study would be necessary for this (Baron $\&$ Kenny, 1986). However, the results do support the hypothesis that PA has a direct effect on reading accuracy beyond its effect on sounding out unknown words. It is possible that PA has captured variance attributable to partial decoding that was not picked up on in the nonword task. For example, a child may decode the beginning of a word, which then prompts access to its lexical representation, resulting in the correct pronunciation of the whole word. In addition, as others have argued (Ehri, 2008; Rack, Hulme, Snowling \& Wightman, 1994), PA is likely to affect how easily and efficiently a child learns to recognize words through a "direct mapping" mechanism as well as explicit sounding out. In other words, having well specified phonological representations makes it easier to learn to link written words to these spoken words (whether they are regular or not).

The nonsignificant effect of MA on reading accuracy might suggest that the link between MA and word reading can be explained by the use of morphological strategies at the word level. However, that MA did not predict morphological strategy use means that there is no evidence of a link between MA and reading in the present study. This is in line with some studies that have shown no significant effect of MA on word reading once PA had been accounted for (Deacon \& Kirby, 2004; Mahony et al., 2000; Nagy et al., 2003).

Regarding reading comprehension, MA had a direct effect on reading comprehension after the effect of PA and nonword decoding had been partialed out. It appears that general awareness of morphemes helps comprehension in a broader sense, above the word level, perhaps because it reflects a metalinguistic awareness of semantics and syntax that makes the meaning of sentences more transparent. The nonsignificant contribution of PA to reading comprehension is consistent with previous work (Muter et al., 2004), although in the York Assessment of Reading for Comprehension, it is perhaps enhanced by the experimenter providing words that the child cannot decode, therefore reducing dependence on phonology for comprehension.

\section{Possible limitations and further research}

One limitation of the current research is that the subgroups were not perfectly matched in terms of the severity of their deficits. This implies that the finding that 
children with low language and average PP at school entry will not develop difficulties should be treated with caution, because these children also had a slightly milder language impairment than those with poor language and poor PP. The average groups were also generally poorer than the original no-risk group (standard scores $<100$ ); therefore, the dissociation between skills in the single deficit groups (15 points) was perhaps not big enough to display potential interactions between PP and language. However, this is not unusual in studies of this nature (e.g., Nathan, Stackhouse, Goulandris, \& Snowling, 2004) and demonstrates that the two skills are not completely independent. Finally, the results of the regression analyses to predict reading accuracy and comprehension should be treated with caution because of the small sample size and relatively high association between variables. Future researchers may wish to investigate these relationships in a larger sample of typically developing children to make the results more generalizable.

\section{Conclusions}

This study provides significant steps forward in understanding the early predictors of explicit PA and MA and the reasons behind their link with reading. First, it was shown that children with poor PP skills at the start of school went on to develop poorer PA and MA 3 years later. This finding has educational value because during early schooling, teachers may not have time to determine precise levels of skill, but they are likely to be able to dichotomize children in their class as either poor or average based on their own observations. Consequently, a clear group may be selected for additional support. Second, we found that children in middle childhood were for the most part using phonological strategies to read morphologically complex words. As a result, it may be beneficial for teachers to include more specific teaching of morphemes such that children learn to link morphology to the reading and spelling of new words. Third, it was shown that PA has a direct effect on reading accuracy and MA has a direct effect on reading comprehension independent from strategy use at the word level. This highlights the potential usefulness of teaching PA and MA as skills in their own right without having to consistently focus on orthography-phonology mappings.

\section{APPENDIX A}

Nonwords and phoneme to delete in the dynamic phoneme deletion test chee, $\mathrm{ch}$ pim, $\mathrm{m}$ dreet, $\mathrm{t}$ zonk, $n \quad$ shreb, sh veng, ng griver, $v \quad$ flirmab, 1 glorpid, $p$ fowsking, $\mathrm{s}$ toksit, $\mathrm{s} \quad$ lexed (lekst), $\mathrm{k}$ quant (kwant), k
Prompt

1. Repeat the question. Pronounce word slowly

2. "What comes before and after the ... in ...?"

3. "Can you tell me each sound in ...?"

4. "What's the first sound you hear in ... ?"

5. "There are ... sounds in ... What are they?" 
6. Model segmentation of word with blocks

7. "Now repeat each sound after me"

8. "What do these sounds make together?" Point to the blocks in the first and/or last segment of word

9. Give pronunciation of first and last segment. "Now we put both parts together to get ... without the. ... What do we get?"

Nonwords in the dynamic morpheme test wug, wugs zib, zibbing nazz, nazzes heaf, heaves quock, quockier nizz, nizzes' zing, zang nizz, nizzes zib, zibber splow, splowed quock, quocky quock, quockiest wug, wug-house thank, thankful

\section{Prompt}

1. Repeat question with real-word example

2. Give answer with real word

3. Explain rule, ask for affix/inflection, e.g., "When there's two of something, you add a sound to the end of the word. What is it?"

4. Give answer with real word, emphasize affix/inflection

5. Give affix/inflection

6. Demonstrate with written aid

Nonwords in the phonological and morphological reading test

$\begin{array}{lll}\text { bish } & \text { mishope } & \text { unishaped } \\ \text { mive } & \text { cophant } & \text { unimpute } \\ \text { anthive } & \text { lave } & \text { smaped } \\ \text { healthive } & \text { amphal } & \text { unirritate } \\ \text { hophouse } & \text { amazive } & \text { kished } \\ \text { unimatch } & \text { lishing } & \text { dancive } \\ \text { unisided } & \text { mishammer } & \end{array}$

Sentences in the phonological and morphological spelling test

We usually deave in the morning but yesterday we deaved in the afternoon.

A dinosaur with a knot in his tail is called a knotosaurus.

A person who soams is a soamer.

A saughty baby is full of saughtiness.

The boy was not fetted well, he was misfetted.

The cat was very gringy, it was the gringiest cat in the street.

A man who does lagic is a lagician.

I feep very well and yesterday I fept all day.

When a person protes something, they make a protement.

The lady trits a lot. She is terribly tritful.

When my Mum's friend asks her to pon her food again, she says "can you repon my food?" There was a lonely crizz in a cage. When they bought another one, there were two crizzes in the cage.

The house was impossible to heng. It was unhengable. 


\section{ACKNOWLEDGMENTS}

This study was carried out with support from two grants (RES-062-23-0195 and RES000-22-3970) from the Economic and Social Research Council. Thanks to the children, families, and schools involved in data collection.

\section{NOTE}

1. The $t$ tests between raw scores for the low and average group on each of the four PP and the three language variables showed that, in each case, the low group had a significantly poorer score than the average group $(p<.001)$. This shows that group differences were not an artifact of the process of residualizing for age and standardizing against the control group.

\section{REFERENCES}

Anglin, J. M. (1993). Vocabulary development: A morphological analysis. Monographs of the Society for Research in Child Development, 58(10), 1-166.

Apel, K., \& Lawrence, J. (2011). Contributions of morphological awareness skills to word-level reading and spelling in first-grade children with and without speech sound disorder. Journal of Speech, Language, and Hearing Research, 54, 1312-1327.

Baron, R. M., \& Kenny, D. A. (1986). The moderator mediator variable distinction in social psychological-research-Conceptual, strategic, and statistical considerations. Journal of Personality and Social Psychology, 51, 1173-1182.

Berko, J. (1958). The child's learning of English morphology. Word, 14, 150-177.

Berninger, V. W., Abbott, R. D., Nagy, W., \& Carlisle, J. (2010). Growth in phonological, orthographic, and morphological awareness in Grades 1 to 6. Journal of Psycholinguistic Research, 39, 141163.

Bowers, P. N., Kirby, J. R., \& Deacon, S. H. (2010). The effects of morphological instruction on literacy skills: A systematic review of the literature. Review of Educational Research, 80, 144179.

Bridges, M., Catts, H., \& Diane, N. (2011). The use of dynamic screening of phonological awareness to predict reading outcomes. Paper presented at the Society for the Scientific Study of Reading, St. Pete Beach, FL.

Byrne, B. (1993). Learning to read in the absence of phonemic awareness? A comment on Cossu, Rossini and Marshall (1993). Cognition, 48, 285-288.

Carlisle, J. F. (2000). Awareness of the structure and meaning of morphologically complex words: Impact on reading. Reading and Writing, 12, 169-190.

Carlisle, J. F., \& Nomanbhoy, D. M. (1993). Phonological and morphological awareness in 1st-graders. Applied Psycholinguistics, 14, 177-195.

Carroll, J. M., \& Myers, J. M. (2010). Speech and language difficulties in children with and without a family history of dyslexia. Scientific Studies of Reading, 14, 247-265.

Carroll, J. M., Snowling, M. J., Hulme, C., \& Stevenson, J. (2003). The development of phonological awareness in preschool children. Developmental Psychology, 39, 913-923.

Casalis, S., \& Cole, P. (2009). On the relationship between morphological and phonological awareness: Effects of training in kindergarten and in first-grade reading. First Language, 29, 113-142.

Casalis, S., \& Louis-Alexandre, M. F. (2000). Morphological analysis, phonological analysis and learning to read French: A longitudinal study. Reading and Writing, 12, 303-335.

Castles, A., Holmes, V. M., Neath, J., \& Kinoshita, S. (2003). How does orthographic knowledge influence performance on phonological awareness tasks? Quarterly Journal of Experimental Psychology, 56A, 445-467.

Chiat, S. (2001). Mapping theories of developmental language impairment: Premises, predictions and evidence. Language and Cognitive Processes, 16, 113-142.

Coltheart, M., Rastle, K., Perry, C., Langdon, R., \& Ziegler, J. (2001). DRC: A dual route cascaded model of visual word recognition and reading aloud. Psychological Review, 108, 204256. 
Cooper, D. H., Roth, F. P., Speece, D. L., \& Schatschneider, C. (2002). The contribution of oral language skills to the development of phonological awareness. Applied Psycholinguistics, 23, 399-416.

Cunningham, A. J., \& Carroll, J. M. (2011). Age and schooling effects on early literacy and phoneme awareness. Journal of Experimental Child Psychology, 109, 248-255.

Deacon, S. H., \& Kirby, J. R. (2004). Morphological awareness: Just "more phonological"? The roles of morphological and phonological awareness in reading development. Applied Psycholinguistics, $25,223-238$.

Ehri, L. C. (2008) Development of sight word reading: Phases and findings. In M. J. Snowling \& C. Hulme (Eds.), The science of reading: A handbook. Oxford: Blackwell.

Gombert, J. E. (1992). Metalinguistic development. Chicago: Harvester Wheatsheaf.

Grigorenko, E. L., \& Sternberg, R. J. (1998). Dynamic testing. Psychological Bulletin, 124, 75-111.

Hulme, C., Hatcher, P. J., Nation, K., Brown, A., Adams, J., \& Stuart, G. (2002). Phoneme awareness is a better predictor of early reading skill than onset-rime awareness. Journal of Experimental Child Psychology, 82, 2-28.

Kieffer, M. J., \& Lesaux, N. K. (2012). Development of morphological awareness and vocabulary knowledge in Spanish-speaking language minority learners: A parallel process latent growth curve model. Applied Psycholinguistics, 33, 23-54.

Kirk, C., \& Gillon, G. T. (2007). Longitudinal effects of phonological awareness intervention on morphological awareness in children with speech impairment. Language Speech and Hearing Services in Schools, 38, 342-352.

Larsen, J. A., \& Nippold, M. A. (2007). Morphological analysis in school-age children: Dynamic assessment of a word learning strategy. Language Speech and Hearing Services in Schools, 38, 201-212.

Lyster, S.-A. H. (2002). The effects of morphological versus phonological awareness training in kindergarten on reading development. Reading and Writing, 15, 261-294.

Mahony, D., Singson, M., \& Mann, V. (2000). Reading ability and sensitivity to morphological relations. Reading and Writing, 12, 191-218.

McBride-Chang, C., Cho, J. R., Liu, H. Y., Wagner, R. K., Shu, H., Zhou, A. B., et al. (2005). Changing models across cultures: Associations of phonological awareness and morphological structure awareness with vocabulary and word recognition in second graders from Beijing, Hong Kong, Korea, and the United States. Journal of Experimental Child Psychology, 92, 140160.

Melby-Lervag, M., Lyster, S.-A. H., \& Hulme, C. (2012). Phonological skills and their role in learning to read: A meta-analytic review. Psychological Bulletin, 138, 322-352.

Muter, V., Hulme, C., Snowling, M. J., \& Stevenson, J. (2004). Phonemes, rimes, vocabulary, and grammatical skills as foundations of early reading development: Evidence from a longitudinal study. Developmental Psychology, 40, 665-681.

Nagy, W., Berninger, V. W., \& Abbott, R. D. (2006). Contributions of morphology beyond phonology to literacy outcomes of upper elementary and middle-school students. Journal of Educational Psychology, 98, 134-147.

Nagy, W., Berninger, V., Abbott, R., Vaughan, K., \& Vermeulen, K. (2003). Relationship of morphology and other language skills to literacy skills in at-risk second-grade readers and at-risk fourthgrade writers. Journal of Educational Psychology, 95, 730-742.

Nathan, L., Stackhouse, J., Goulandris, N., \& Snowling, M. J. (2004). The development of early literacy skills among children with speech difficulties: A test of the "Critical age hypothesis." Journal of Speech, Language, and Hearing Research, 47, 377-391.

Nunes, T., \& Bryant, P. (2006). Improving literacy by teaching morphemes. London: Routledge.

Nunes, T., Bryant, P., \& Olsson, J. (2003). Learning morphological and phonological spelling rules: An intervention study. Scientific Studies of Reading, 7, 289-307.

Osborne, J. (2002). Notes on the use of data transformations. Practical Assessment, Research \& Evaluation 8(6). Retrieved April 18, 2012, from http://PAREonline.net/getvn.asp?v=8\&n=6

Rack, J., Hulme, C., Snowling, M. J., \& Wightman, J. (1994). The role of phonology in young children learning to read words: The direct mapping hypothesis. Journal of Experimental Child Psychology, 57, 42-71.

Rose, J. (2006). Independent review of the teaching of early reading: Final report (pp. 1-240). London: United Kingdom Department for Education and Skills. 
Snowling, M. J., Gallagher, A., \& Frith, U. (2003). Family risk of dyslexia is continuous: Individual differences in the precursors of reading skill. Child Development, 74, 358-373.

Snowling, M. J., Stothard, S. E., Clarke, P., Bowyer-Crane, C., Harrington, A., \& Truelove, E. (2009). York Assessment of Reading for Comprehension. London: GL Education Group.

Spector, J. E. (1992). Predicting progress in beginning reading-Dynamic assessment of phonemic awareness. Journal of Educational Psychology, 84, 353-363.

Van der Lely, H. K. J., Rosen, S., \& Adlard, A. (2004). Grammatical language impairment and the specificity of cognitive domains: Relations between auditory and language abilities. Cognition, 94, 167-183.

Wagner, R. K., Torgesen, J. K, Rashotte, C. A., Hecht, S. A., Barker, T. A., Burgess, S. R., et al. (1997). Changing relations between phonological processing abilities and word level reading as children develop from beginning to skilled readers: A 5-year longitudinal study. Developmental Psychology, 33, 468-479.

Walley, A. C. (1993). The role of vocabulary development in children's spoken word recognition and segmentation ability. Developmental Review, 13, 286-350.

Wiig, E. H., Secord, W. A., \& Semel, E. (2006). Clinical Evaluation of Language Fundamentals. London: Harcourt Assessment.

Wilson, M. D. (1988). The MRC Psycholinguistic Database: Machine readable dictionary, version 2. Behavioural Research Methods, Instruments, and Computers, 20, 6-11.

Wolter, J. A., Barger, H., Pike, K., Atwood, B., \& Martin, N. (2011). Dynamic assessment of morphological awareness and third-grade literacy achievement. Paper presented at the Society for the Scientific Study of Reading, St. Pete Beach, FL.

Wolter, J. A., Wood, A., \& D'Zatko, K. W. (2009). The influence of morphological awareness on the literacy development of first-grade children. Language Speech and Hearing Services in Schools, 40, 286-298. 